\title{
How can we grow and lead
2019 Charles FM Saint Lecture Association of Surgeons of South Africa
}

\author{
OJ Garden \\ Professor Emeritus, Edinburgh Surgery Online, University of Edinburgh
}

Corresponding author, email: o.j.garden@ed.ac.uk

'Education is the most powerful weapon which you can use to change the world.'

Nelson Mandela

It is a privilege to deliver this prestigious lecture in the name of Charles FM Saint who was the first Professor of Surgery at the University of Cape Town in 1920. He is known widely in medicine for the triad that bears his name but he was also recognised by many as a gifted and inspirational surgical teacher and trainer. ${ }^{1}$ He gave priority to teaching as opposed to research when involved in establishing the first medical school in South Africa. It is estimated that some 1300 students passed through his hands during his tenure of the chair of surgery. Furthermore, his two-fold approach to teaching surgery included addressing the principles and the application of the principles in practice around clinical teaching and surgical pathology. ${ }^{2}$ His legacy has continued over the last 100 years at the University of Cape Town which continues to set high standards in surgical innovation, education and research.

I have been fortunate in following a long line of renowned surgeons who have held the Regius Chair of Clinical Surgery which was founded at the University of Edinburgh in 1803. For the purposes of this lecture, it is perhaps appropriate to draw a comparison with the third Regius Professor, Joseph Lister, whose research into antiseptic surgery had such a major impact on the practice of surgery in the second half of the $19^{\text {th }}$ century. During his 21-year tenure of the regius chairs of surgery in Glasgow and Edinburgh, it is estimated that he taught some 1600 students in Scotland. Lister was one of many teachers who had established Edinburgh's longstanding reputation as a centre of medical learning and enlightenment, attracting many international students and training doctors to the capital city.

Edinburgh medicine has continued to have significant international outreach but its more recent global influence in surgical education has resulted from a collaboration between the historical rivals, the University of Edinburgh and the Royal College of Surgeons of Edinburgh. In 2006, they signed a memorandum of understanding which aimed to combine their respective strengths in the professional and academic support of surgeons. At that time, there had been substantial changes in surgical training worldwide. Reduced working hours were enforced under British and European legislation $^{3}$ and the introduction of run-through and core training programmes in the United Kingdom had resulted in the surgical trainee having less exposure to common surgical conditions and procedures that previously had very much formed part of the traditional basis of surgical training. ${ }^{4}$ Trends to reduce working hours were also evident in other continents. ${ }^{5,6}$ In the United Kingdom, there was often inconsistency in teaching provision of knowledge and educational support as trainees prepared for the first significant hurdle of their early training, the membership examination of the Royal College of Surgeons (MRCS), normally taken during the first 2 years of basic surgical training. Further in the career training path, there was a tradition that a period of time should be taken out of training to complete a period of full-time research training, although only a minority who completed a postgraduate degree would necessarily commit to an academic career.

In response to these changes, a modular part-time online master's degree was launched in 2007 by the University of Edinburgh and the Royal College of Surgeons of Edinburgh (RCSEd). ${ }^{7}$ This Master in Surgical Sciences programme, often referred to at that time as the Edinburgh Surgical Sciences Qualification (ESSQ) was based on the MRCS curriculum but was tailored to be equally applicable to the early years of surgical training programmes worldwide. The programme is delivered on a dedicated virtual learning environment (VLE) and provided ready access to learning material tailored to the professional needs of surgical trainees. The flexible and readily accessible delivery of course content enables students to measure their progress through the individual components of the MRCS curriculum, while peer support and senior mentorship are provided during this critical phase of their professional development (Figure 1). Online clinical case scenarios are used with specific objectives that underpin the curriculum in the applied surgical sciences of anatomy, radiology, physiology, pathology and bacteriology in the first year, with modules in the assessment and care of the surgical patient, research, and communication skills in year 2. A sense of community and exchange of knowledge is provided through assessed asynchronous discussion boards. Progress is monitored by tutors and knowledge assessed with multiple choice and extended matching item questions 


\section{UK Surgical Training Structure}

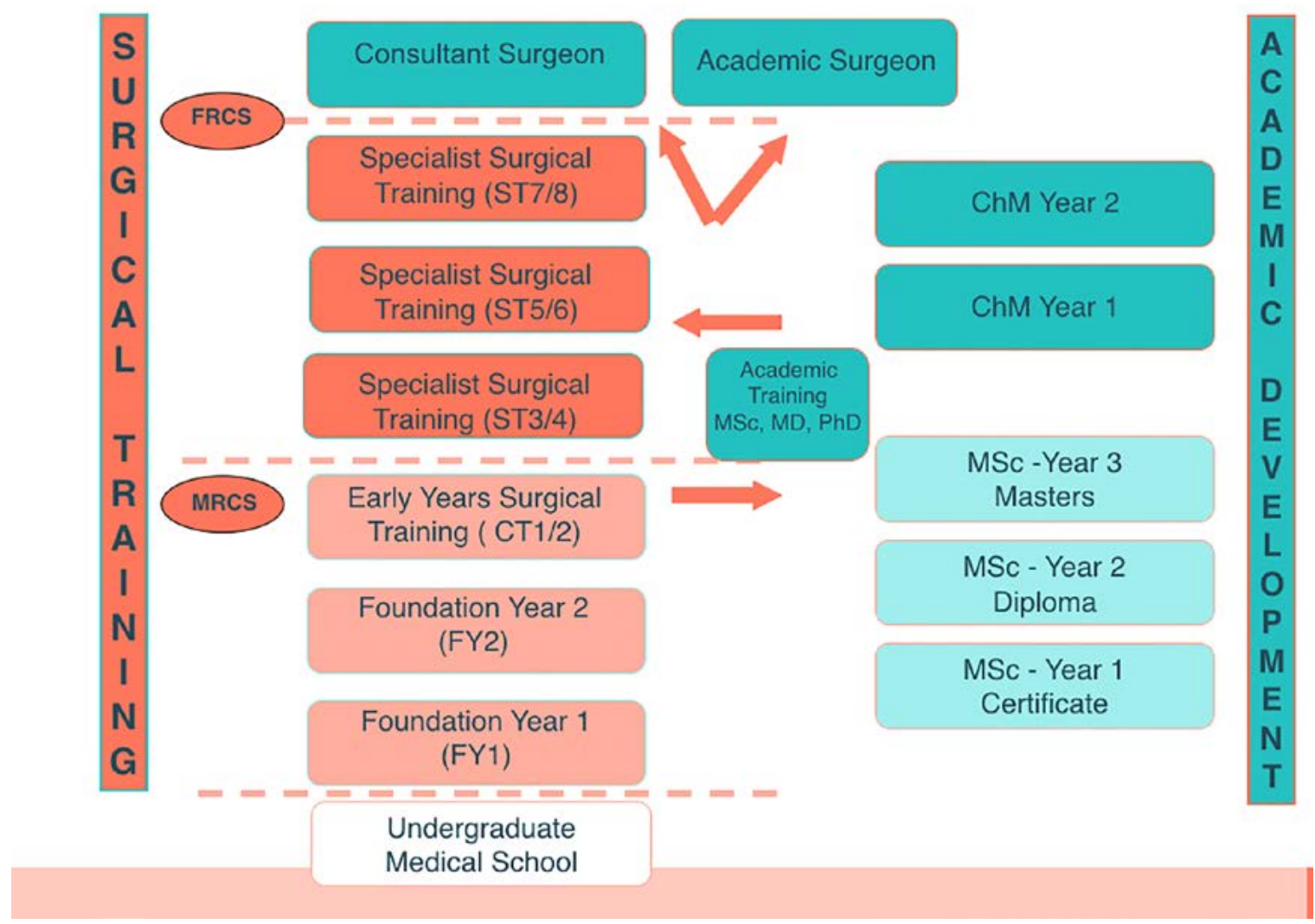

Figure 1: Summary of the training programme structure in the United Kingdom and the positioning of the three-year online Master in Surgical Sciences (MSc) and the two-year online Master in Surgery (ChM) programmes

in each of the first two years. In the final year, the trainee undertakes a supervised project which requires approval of a submitted outline submission of an e-poster as well as completion of a dissertation, all of which are assessed, with successful completion resulting in the awarding of a master's degree. Students can withdraw from the programme at the end of years one or two and receive a certificate or diploma, if assessment milestones have been met. ${ }^{8}$

The MSc in Surgical Sciences was the fastest recruiting master's programme at the University of Edinburgh when it was launched and quickly extended to a wider global audience since its mode of delivery allowed students to study flexibly, anywhere, anytime and on any device. Within four years, a further two-year online master's programme, $\mathrm{ChM}$ in General Surgery, was launched to support trainees approaching the end of general surgical training with content built on the curriculum of the exit Fellowship examination. Further programmes ensued to support training in trauma and orthopaedics, urology, vascular surgery and ophthalmology. By 2019, over 1000 students had graduated and by the end of 2019, over 2000 training surgeons had enrolled on these programmes (Figure 2). An MSc in Patient Safety and Clinical Human Factors was also launched in September 2018 to support any graduate allied health care professional wishing to develop knowledge and skills in these areas.

Although originally intended to support primarily a UK audience, the global outreach of the programmes has been remarkable with substantial recruitment in Australasia and sub-Saharan Africa, where an increasing scholarship programme has supported training surgeons after working in challenging circumstances with varied local educational support. Since 2000, the programmes have benefited from regular scholarship funding from an educational grant from Johnson and Johnson targeted specifically at supporting training surgeons in Malawi. That country has the lowest doctor staffing levels in southern Africa with less than 20 qualified general surgeons serving an estimated population of 17 million. The challenge has always been to retain surgeons in their own country when they consider pursuing training opportunities overseas. In the last ten years, 30 training surgeons have received scholarships and enrolled for the MSc in Surgical Sciences. Eighteen of these have graduated with a master's and one at certificate level. Seven are currently studying on the programme, one student changed career and two exited without an award. A further student moved to South Africa but completed the master's programme without full scholarship support. All but one of these scholarship students have remained to practice in Malawi and almost half of the enrolled students have been female. There are good examples of how this educational support has added to other efforts to build health care capacity in Malawi. Several graduates are now in leadership roles in surgery in their own country. Some have also now gone on to enrol in the $\mathrm{ChM}$ programmes using these as a means of developing or reinforcing their subspecialty knowledge.

It is evident that there is a strong demand for delivering academic and professional support to training surgeons globally in this way. The programmes have the potential to support trainees throughout their surgical training. The MSc in Surgical Sciences programme allows the student to acquire an understanding of the applied basic surgical sciences while the ChM programmes support the surgeon in understanding the key knowledge base around advanced surgical practice. A past review of student performance on the 


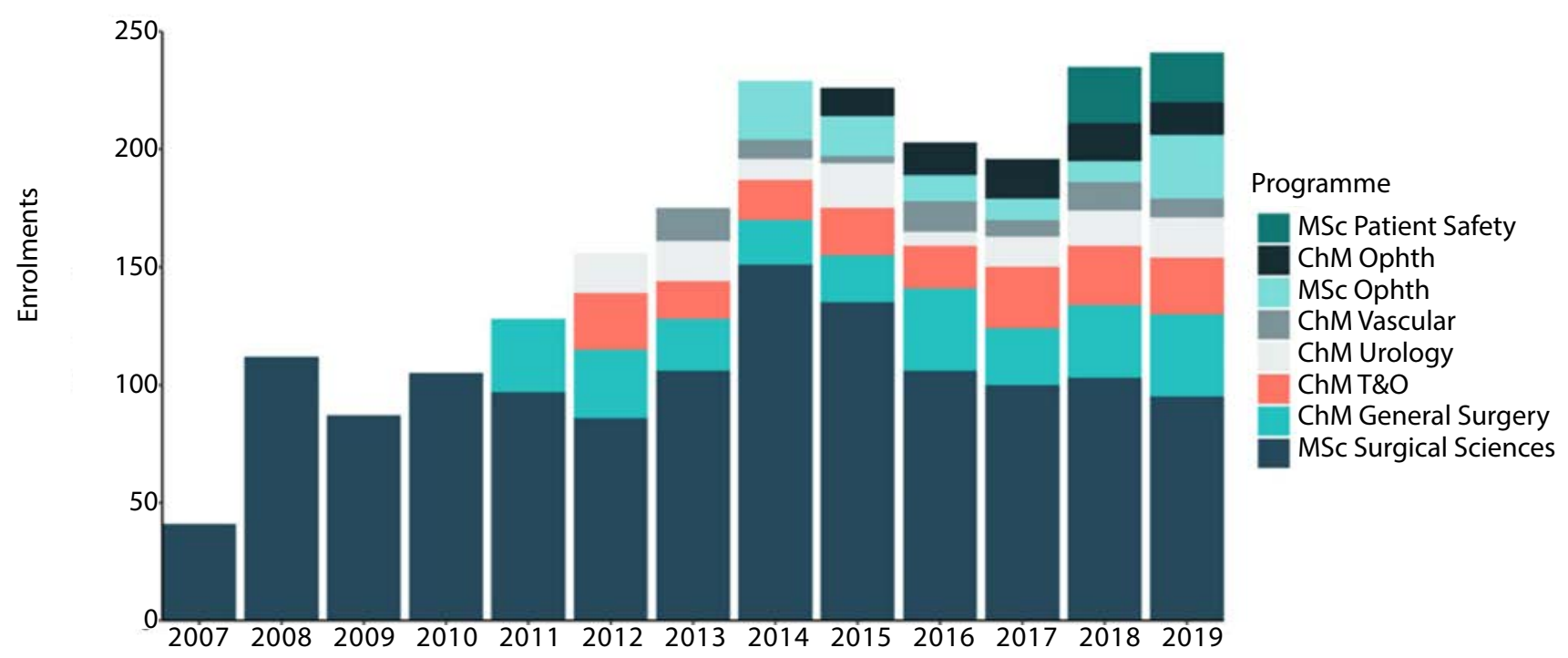

Figure 2: Student enrolment to online master's programmes for the period 2017-2019

programmes indicated that MSc students had significantly higher MRCS pass rates than non-enrolled students $(67 \%$ vs $51 \% ; p<0.01) .{ }^{8}$ It is evident that the programmes better prepare students for the MRCS or FRCS professional examination, although experience also suggests that those preparing for equivalent surgical qualifications globally also benefit. While the intention is to support professional development, the master's programmes do not replace but rather complement in-workplace training and for others, perhaps address deficiencies. For some, it is an opportunity for ambitious trainees to acquire additional qualifications which would enhance their portfolio and career development as well as proving all with the essential 'academic tools' to support life-long learning. For prospective academic surgeons, the master's programmes are a chance to acquire a qualification which identifies their career intentions and a credible base for career development. Moreover, the very online nature of the master's programmes has ensured equity of access to a global audience.

The success of the programmes has not just been built on the Edinburgh surgery 'brand' and through scholarship funding. The VLE platforms allow flexible, ready access to a supportive community with other students and tutors. The design of the programme is justified by the pedagogical e-learning principles, whereby students are supported as members of an online community with clearly defined learning objectives and use of materials that are active, engaging, collaborative, and relevant. This approach also fits with modern learning methods and $90 \%$ of enrolled students would have recommended the programme. ${ }^{7}$ There is strong trainee engagement as they prepare for their professional milestones. There is increased experiential learning and access to academic opportunity which underpins future evidence-based surgical practice. For those in UK-based training programmes, this can be achieved without the potential for financial loss as a consequence of pursuing fulltime postgraduate study.

Providing quality training to a surgeon will remain challenging. Within modern training programmes, the greater focus is often on the acquisition of technical skills. Clinical skills and the preoperative and postoperative management of patients can be learnt in the workplace but online education would appear to have a role in addressing the shortcomings of self-directed learning and where educational programmes may be poorly structured. Charles Saint may not have totally approved of this modern approach to surgical training, but he would surely have been impressed by the rigor with which the development and delivery of the programmes has been undertaken.

\section{Conflicts of interest}

Director of Edinburgh Surgery Online, University of Edinburgh.

\section{REFERENCES}

1. Louw JH. Charles FM Saint. S Afr Med J. 1973;47:282.

2. Saint CFM. Some recollections of the early days of the medical school, Cape Town. S Afr Med J. 1963;37:49-51.

3. Great Britain Department of Health. Protecting Staff; Delivering Services: Implementing the European Working Time Directive for Doctors in Training. London, UK: Great Britain Department of Health; 2003. p. 1-3.

4. Moonesinghe SR, Lowery J, Shahi N, et al. Impact of reduction in working hours for doctors in training on postgraduate medical education and patients' outcomes: systematic review. BMJ. 2011;342:d1580.

5. Gough IR. The impact of reduced working hours on surgical training in Australia and New Zealand. Surgeon. 2011;9:S8S9.

6. Kairys JC, McGuire K, Crawford AG, et al. Cumulative operative experience is decreasing during general surgery residency: a worrisome trend for surgical trainees? J Am Coll Surg. 2008;2(6):804-11.

7. Edinburgh Surgery Online. Available from: www. edinburghsurgeryonline.com.

8. Smith PJ, Wigmore SJ, Paisley A, et al. Distance learning improves attainment of professional milestones in the early years of surgical training. Ann Surg. 2013;258:838-43. 